\title{
High-Frequency Issues Using Rotating Voltage Injections Intended For Position Self-Sensing
}

\author{
Fabien Gabriel, Member, IEEE, Frederik De Belie, \\ Xavier Neyt, Member, IEEE, Philippe Lataire
}

\begin{abstract}
The rotor position is required in many control schemes in electrical drives. Replacing position sensors by machine self-sensing estimators increases reliability and reduces cost. Solutions based on tracking magnetic anisotropies through the monitoring of the incremental inductance variations are efficient at low-speed and standstill operations. This inductance can be estimated by measuring the response to the injection of high-frequency signals. In general however, the selection of the optimal frequency is not addressed thoroughly. In this paper, we propose discrete-time operations based on a rotating voltage injection at frequencies up to one third of the sampling frequency used by the digital controller. The impact on the rotation-drive, the computational requirement, the robustness and the effect of the resistance on the position estimation are analyzed regarding the signal frequency.
\end{abstract}

Index Terms-AC motor drives, Sensorless control, Highfrequency signal-injection, Permanent-magnet (PM) machine

\section{NOMENCLATURE}

$\alpha \beta \quad$ axes of the stationary frame;

qd axes of the synchronous frame;

xy axes of the anisotropy frame;

$\varphi_{\mathrm{x}} \quad$ angle of the anisotropy frame with respect to $\alpha \beta$;

$\underline{x}$ denotes a space vector, that can be the current $\underline{i}$, the voltage $\underline{v}$, the flux $\psi$ or the back-emf $\underline{e}_{\mathrm{PM}}$;

$a$ denotes an anisotropic parameter, that can be the resistance $\boldsymbol{r}$ or the incremental self-inductance $\boldsymbol{l}_{\mathrm{t}}$;

$a_{+}, a_{-}$positive and negative parameters, corresponding to $a$;

$\underline{x}(t)$ continuous-time value;

$\nu_{\mathrm{s}}, T_{\mathrm{s}}$ sampling frequency and sampling period: $\nu_{\mathrm{s}}=1 / T_{\mathrm{s}}$; $\underline{x}\left(t^{[k]}\right)$ samples of the value at sampling instants $t^{[k]}$;

$\underline{\tilde{x}}^{[k]}$ mean of $\underline{x}(t)$ between two sampling instants;

Copyright $\odot 2009$ IEEE. Personal use of this material is permitted. However, permission to use this material for any other purposes must be obtained from the IEEE by sending a request to pubs-permissions@ieee.org

Manuscript received June 1st, 2012. Revised in September 20, 2012 Accepted for publication November 6, 2012. This work is financed by the Belgian government as part of the Belgian Defense research program F0709. It is performed in collaboration with UGent in the framework of the Interuniversity Attraction Poles program IUAP P6/21. The UGent authors also wish to thank the Research Foundation-Flanders (FWO) for the financial support in the framework of project number G.0665.06.

Fabien Gabriel and Xavier Neyt are with the Dept. of Communication, Information, Systems and Sensors (CISS), Royal Military Academy (RMA), 1000 Brussels, Belgium (e-mail: fgabriel@elec.rma.ac.be xavier.neyt@elec.rma.ac.be)

Frederik De Belie is with the Dept. Electrical Energy, Systems \& Automation (EESA), Ghent University (UGent), 9000 Gent, Belgium (e-mail frederik.debelie@ugent.be)

Philippe Lataire is with the Dept. Electric Engineering and Energy Technology (ETEC), Vrije Universiteit Brussel (VUB), 1050 Ixelles, Belgium (email:plataire@vub.ac.be) $\underline{\bar{x}}^{[k]} \quad$ average of two consecutive samples;

$\delta \underline{x}^{[k]}$ backward difference between two samples;

$\underline{x}_{\mathrm{c}} \quad$ contribution of the normal rotation-drive operations; $\underline{x}_{\mathrm{i}} \quad$ contribution of signals injected for the self-sensing;

$\left\{\omega_{\mathrm{c}}\right\}$ frequencies (in radian $\omega=2 \pi \nu$ ) related to $\underline{x}_{\mathrm{c}}$;

$\left\{\omega_{\mathrm{i}}\right\}$ frequencies related to $\underline{x}_{\mathrm{i}}$;

$\underline{X}(\mathrm{z})$ z-transform of the discrete-time value $\underline{x}$;

$\underline{X}\left(\mathrm{e}^{j \omega T_{\mathrm{s}}}\right) \quad$ Fourier-transform of the discrete-time value $\underline{x}$;

\section{INTRODUCTION}

Many closed-loop control schemes used in electrical drives, such as most vector-control schemes, require the knowledge of the rotor position [1], [2]. This position can be measured by external dedicated sensors, such as encoders, resolvers and hall-effect sensors. However, more and more, these sensors are removed [3] in order to 1) increase the reliability of the drive by reducing the risk of failure, 2) reduce the cost of these external sensors or 3) to save space. This strategy is often referred to as position/motion-sensorless or self-sensing control. In this paper, the latter terminology is preferred since it reflects the principle: electromechanical phenomenons in the machine itself, that vary with the rotor position, are used to estimate the rotor position. These phenomenons can be observed and tracked from measurable electrical variables, such as currents and voltages [1], [2], [4], [5].

Here, we consider only self-sensing methods based on the current samples used for the digital current control, and on the knowledge of the supplied voltage. Methods using additional sensors can be very efficient, but these sensors introduce additional costs and processing. Among them, we find those using current-slope measurements in order to detect current variations in response to a pulse injection [6], to detect the current ripples due to the pulse-width modulation (PWM) [7] or during the zero-sequence of the PWM [8]; those using very high-frequency digital sampling instead of current slope sensors [9]; those using current samples at specific instants during the PWM [10], [11]; and those using zero-sequence voltage measurements [12]. They are not further discussed in this document.

At high speeds, the back-emf is a reliable source to estimate the rotor position without much effort [13], [14]. Its signalto-noise quality however decreases with the rotation speed. Note that some methods do not involve directly the back-emf, but estimate the linking magnetic flux. They are then sometimes referred to as fundamental-model-based methods [15] 
or simply stator-flux-based methods using MRAS observer [16] or extended Kalman filters [17]. At low rotation speed and standstill, an estimation of the rotor position can be obtained from anisotropic properties linked to the rotor position [8], [12], [18]-[36], assuming some feasibility considerations [37]-[39]. These anisotropies can be due to variations in the rotor geometry or to magnetic saturation effects in the iron [19] and are revealed through anisotropic parameters, such as the incremental inductance. Special attention can be given to the machine design in order to increase their anisotropy [38], [40]. It is also possible to increase the anisotropy of existing machines by adding a copper turn wound around the poles [41], [42]. The comparison between the different self-sensing methods are largely discussed in [15]. Some back-emf-based methods also take the anisotropy into account in the model, even if the anisotropy is not used to estimate the position [43]. Solutions that combine the back-emf-based method at low-speed and the anisotropy-based method at higher-speed have been implemented in [9], [44]. Hybrid solutions using both methods simultaneously in order to compensate for their respective error sources are proposed in [13], [45]-[47]. This paper focuses on anisotropy-based position self-sensing methods intended for the vector control of permanent-magnet (PM) machines, that naturally present some anisotropic properties.

Misalignment between the anisotropy and the real rotor position can be due to significant stator currents [22], [23], [25], [33], [36], [39], [47]-[49], to the so-called secondary and multiple saliencies [23], [25], [48], or to more general spatial (slots) harmonics related to the conductor distributions and the nonsinusoidal magnetic-field [24], [25], [50]. These issues are largely addressed in the literature.

In the vast majority of anisotropy-based strategies without extra sensors, the anisotropy is tracked performing highfrequency signal injection in addition to the rotation-drive operating signals (also sometimes referred to as "fundamental" operating signals). In some specific situations, the variations of the rotation-drive operating signals can be large enough to perform the estimation without signal injection. E.g. [51] and [28] propose solutions based on the signal variations in a direct-torque controller. These specific cases are not studied here. Many different types of signal injection can be used: testpulse trains [6], [10], [11], [28], [29], pulse-width modulation (PMW) modifications [9], carrier-based pulsating and rotatingsignals injection [11], [12], [23], [25]-[27], [30], [32], [44]. In some pulse-train injection strategies, it is required to interrupt the rotation-drive operations during short periods [6], leading to some distortions on the drive. An improved pulse-train strategy is proposed in [29] using test-pulse signals without affecting the rotation-drive operations. Comparisons between several signal injections are proposed by [20], [52]. This paper focuses on the rotating-signal injection that yields good performances without initial knowledge of the parameters. The impact of the rotating-signal injection on the rotation-drive operation is discussed in this paper.

Besides [27], [30], [32], [35], [53], the resistance impact is often neglected in signal-injection operations, assuming an ideal inductive machine. The eddy currents however increase with the frequency and may significantly affect the apparent resistance value [27], [32], [34], [54], [55], leading to positionestimation errors [23], [27]. This issue is considered in this paper.

The frequency of the injected signals is often selected between $400 \mathrm{~Hz}$ and $2 \mathrm{kHz}$ [19], [56] and many papers introduce self-sensing using continuous-time operations. We propose here to study discrete-time operations up to one third of the sampling frequency used by the current controller, which is the maximum possible frequency defining rotating signals. The benefits of the proposed method are analyzed regarding disturbing interactions between the rotation-drive and the self-sensing operations, regarding the filtering and the computational requirement, the robustness and the impact of the apparent resistance.

Section II describes the discrete-time model of the permanent-magnet machine and states the expressions between voltages and currents; Section III addresses the principles of the signal injection, proposes the discrete-time operations and analyzes the benefits using higher signal frequencies; Section IV discusses the resistance impact with experimental cases; Section V shows experimental results using a signal injected at one third of the sampling frequency and Section VI concludes.

\section{Model of the Permanent-Magnet Machine}

\section{A. Continuous-time Circuit Model}

The machine model is described using the concept of space vectors in a complex frame [57]. The space vector $\underline{v}$ refers to the supply voltage applied to the stator circuit terminals and $\underline{i}$ to the electrical current flowing through the terminals. The magnetic flux $\psi$ linked by the stator circuit can be divided in two main contributions: 1) the contribution of the currents $\underline{i}$ written $\underline{\psi}_{\mathrm{S}}=\boldsymbol{l} \underline{\boldsymbol{i}}$ where $\boldsymbol{l}$ is the stator inductance and 2) the contribution of the PM written $\underline{\psi}_{\mathrm{PM}}$. Since the statorcircuit model uses the derivative of the flux, we also define the incremental inductance $\boldsymbol{l}_{\mathrm{t}}: d \underline{\psi}_{\mathrm{S}}=\boldsymbol{l}_{\mathrm{t}} d \underline{i}$ [21]; and the back-electromotive force (back-emf) $: \underline{e}_{\mathrm{PM}}=d \underline{\psi}_{\mathrm{PM}} / d t$. In the $\alpha \beta$ stationary reference-frame, the continuous-time relation between the electromagnetic values of the machine statorcircuit is: $\underline{v}=d \psi / d t+r \underline{i}$, where $\boldsymbol{r}$ is the resistance. Replacing all the values yields:

$$
\boldsymbol{l}_{\mathrm{t}} \frac{d \underline{i}}{d t}+\boldsymbol{r} \underline{i}=\underline{v}-\underline{e}_{\mathrm{PM}}
$$

\section{B. Discrete-time Circuit Model}

We assume that the different operations are performed by digital controllers. A discretized model of (1) is therefore required. The current measurements are sampled with a frequency $\nu_{\mathrm{s}}$ at instants $t^{[k]}=k T_{\mathrm{s}}$, where $T_{\mathrm{s}}=1 / \nu_{\mathrm{s}}$ is the sampling period. For convenience, the pulse-width modulated signal (PWM) driving the voltage-source inverter (VSI) is synchronized with the sampling times. Let us defined the mean value of $\underline{x}$ between two sampling times as follows:

$$
\underline{\tilde{x}}^{[k]} \triangleq \frac{1}{T_{\mathrm{s}}} \int_{t^{[k-1]}}^{t^{[k]}} \underline{x}(t) d t
$$



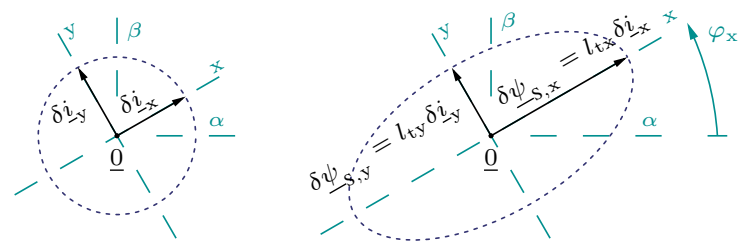

Fig. 1. Illustration of $\delta \psi_{\mathrm{S}}$ related to $\delta \underline{i}$ along the $\mathrm{x}$-axis and along the $y$-axis. The blue dashed lines represent the path drawn by the space vectors when $\delta \underline{i}$ rotates. $\delta \underline{\psi}_{\mathrm{S}}$ describes an ellipse.
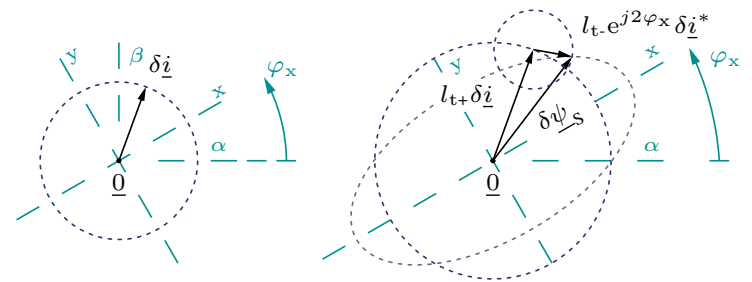

Fig. 2. Illustration of $\delta \psi_{\mathrm{S}}$ related to $\delta \underline{i}$ along an arbitrary direction and modeled by the sum of the positive and negative contributions. The blue dashed lines represent the circle drawn by the two contributions when $\delta \underline{i}$ rotates.

Assuming that the inverter nonlinearities are compensated [4], [31], [36], [52], the mean voltage supplied by the VSI should be equal to the command voltage sent to the PWM-VSI. The backward current difference is:

$$
\delta \underline{i}^{[k]} \triangleq \underline{i}\left(t^{[k]}\right)-\underline{i}\left(t^{[k-1]}\right)
$$

Due to the PWM, the current exhibits ripples between sampling instants and the exact computation of its mean value is not straightforward. We however assume the approximation of an equivalent piecewise-linear mean current computed as the average of two consecutive samples:

$$
\underline{\bar{i}}^{[k]} \approx \frac{i\left(t^{[k]}\right)+\underline{i}\left(t^{[k-1]}\right)}{2}
$$

Applying (2)-(4) on (1) and assuming constant parameters during the sampling periods, the discrete-time stator-circuit model yields:

$$
\boldsymbol{l}_{\mathrm{t}} \frac{\delta \underline{i}^{[k]}}{T_{\mathrm{S}}}+\boldsymbol{r} \underline{\bar{i}}^{[k]}=\underline{\tilde{v}}^{[k]}-\underline{\tilde{e}}_{\mathrm{PM}}^{[k]}
$$

\section{Anisotropic Machine Model}

We assume a constant magnetic state of the machine, i.e. constant saturation level of the iron. This is valid if we consider small estimation periods during which the rotor position does not significantly change, and if we consider small current variations. The magnetic anisotropy is revealed by the variations of the incremental inductance $l_{\mathrm{t}}$ linking $\delta \underline{i}$ to $\delta \underline{\psi}_{\mathrm{S}}$ as a function of their orientation. As illustrated in Fig. 1 , the xy frame is defined such that the axes $\mathrm{x}$ and $\mathrm{y}$ are respectively along the directions that correspond to the maximum $l_{\mathrm{tx}}$ and minimum $l_{\mathrm{ty}}$ of the incremental inductance:

$$
\left(\begin{array}{c}
\delta \underline{\psi}_{\mathrm{S}, \mathrm{x}} \\
\delta \underline{\psi}_{\mathrm{S}, \mathrm{y}}
\end{array}\right)=\left(\begin{array}{cc}
l_{\mathrm{tx}} & 0 \\
0 & l_{\mathrm{ty}}
\end{array}\right)\left(\begin{array}{c}
\delta \underline{i}_{\mathrm{x}} \\
\delta \underline{i}_{\mathrm{y}}
\end{array}\right)
$$

The angle of the x-axis with respect to the $\alpha$-axis is called the anisotropy angle and is noted $\varphi_{\mathrm{x}}$. As explained in [4], [24] and as illustrated in Fig. 2, the relation between $\delta \underline{i}$ and $\delta \underline{\psi}_{\mathrm{S}}$ along any direction can be modeled as the contribution of two components:

$$
\delta \underline{\psi}_{\mathrm{S}}=l_{\mathrm{t}} \delta \underline{i}=l_{\mathrm{t}+} \delta \underline{i}+l_{\mathrm{t}-} \delta \underline{i}^{*} \mathrm{e}^{j 2 \varphi_{\mathrm{x}}}
$$

where $l_{\mathrm{t}+}$ is called the positive incremental inductance and $l_{\mathrm{t}}$ is the negative incremental inductance. The second component contains the anisotropy angle through a rotation of the complex conjugate $\delta \underline{i}^{*}$. They are linked to the maximum and minimum values by:

$$
l_{\mathrm{t}+}=\frac{l_{\mathrm{tx}}+l_{\mathrm{ty}}}{2} \quad \& \quad l_{\mathrm{t}-}=\frac{l_{\mathrm{tx}}-l_{\mathrm{ty}}}{2}
$$

Note that these values are affected by significant variations of the stator currents [25], [33], [36].

The anisotropy angle $\varphi_{\mathrm{x}}$ is linked to the total magnetic field $\psi$ [45], that is partly produced by the PM. The anisotropy xy frame is therefore used as an indicator of the synchronous qd frame, defined by the PM orientation. Misalignment must however be corrected if the contribution of the stator currents to the magnetic field becomes significant [49]. Another correction must be performed if $\underline{\psi}_{\mathrm{PM}}$ is not oriented along the d-axis. This is generally due to a nonsinusoidal shape of the magnetic field in the air-gap and to a nonsinusoidal distribution of the stator windings [24], [36]. The misalignment between the xy frame and the qd frame is sometimes referred to as an estimation error. It is however an error only for the purpose of the position self-sensing estimation. Note that if we use the qd frame to define the relation between $\delta \underline{i}$ and $\delta \underline{\psi}_{S}$, a coupling between the $\mathrm{q}$ and $\mathrm{d}$-axis appears due to the misalignment [22]. This is referred to as magnetic cross-coupling [25], [36], [39], [58]. This issue is not further discussed here since we strictly focus on the anisotropy angle estimations, and not on the relation with the PM location.

Assuming that the resistance is also possibly anisotropic [27], [35] and defined similarly to (7), the anisotropic model (5) yields:

$$
\left(\frac{l_{\mathrm{t}+}}{T_{\mathrm{s}}} \delta \underline{i}^{[k]}+r_{+} \underline{\bar{i}}^{[k]}\right)+\left(\frac{l_{\mathrm{t}-}}{T_{\mathrm{s}}} \delta \underline{i}^{[k]}+r_{-} \underline{\bar{i}}^{[k]}\right)^{*} \mathrm{e}^{j 2 \varphi_{\mathrm{x}}}=\underline{\tilde{u}}^{[k]}
$$

where we defined $\underline{u} \triangleq \underline{v}-\underline{e}_{\mathrm{PM}}$.

\section{The z-Transform Of The Anisotropic Machine Model}

The operations can be described using the z-transform of the discrete-time anisotropic-model relation linking the current difference $\delta \underline{i}$ to the mean voltage $\underline{\tilde{u}}$. Let us first introduce the transfer function $D(\mathrm{z})$ linking the $\mathrm{z}$-transform of the mean current $\underline{\bar{I}}(\mathrm{z})=\mathcal{Z}\{\underline{\bar{i}}\}$ to the z-transform of the current difference $\delta \underline{I}(\mathrm{z})=\mathcal{Z}\{\delta \underline{i}\}$. Using (4) and (3) yields:

$$
\delta \underline{I}(\mathrm{z})=D(\mathrm{z}) \underline{\bar{I}}(\mathrm{z}) \quad \Rightarrow \quad D(\mathrm{z})=\frac{2\left(1-\mathrm{z}^{-1}\right)}{1+\mathrm{z}^{-1}}
$$

Secondly, note that the z-transform of a conjugate value $\underline{x}^{*}$ is $\underline{X}^{*}\left(\mathrm{z}^{*}\right)=\mathcal{Z}\left\{\underline{x}^{*}\right\}$ [59]. Using (10) and assuming timeinvariant anisotropy angle and parameters, the z-transform of the anisotropic model (9) can be written as the contribution of 


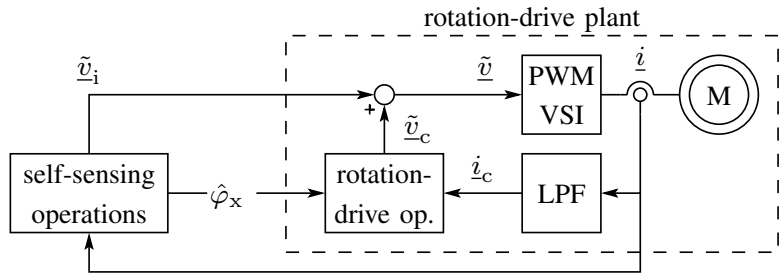

Fig. 3. Flowchart of the rotation-drive plant including a signalinjection and a self-sensing computation

two transfer-functions $Z_{+}(\mathrm{z})$ and $Z_{-}(\mathrm{z})$, that we respectively call positive and negative integral-impedances:

$$
Z_{+}(\mathrm{z}) \delta \underline{I}(\mathrm{z})+Z_{-}(\mathrm{z}) \mathrm{e}^{j 2 \varphi_{\mathrm{x}}} \delta \underline{I}^{*}\left(\mathrm{z}^{*}\right)=\underline{\tilde{U}}(\mathrm{z})
$$

where it is found: $\begin{cases}Z_{+}(\mathrm{z}) & =l_{\mathrm{t}+} / T_{\mathrm{s}}+r_{+} / D(\mathrm{z}) \\ Z_{-}(\mathrm{z}) & =l_{\mathrm{t}-} / T_{\mathrm{s}}+r_{-} / D(\mathrm{z})\end{cases}$

In most of the drives, the voltage is the commanded input signal and the current is the measured output signal. It is therefore required to reverse the relation (11). As explained in the annexes, the reversed relation can be written as the contribution of two transfer-functions $Y_{+}(\mathrm{z})$ and $Y_{-}(\mathrm{z})$, that we respectively call positive and negative derivative-admittances:

$$
Y_{+}(\mathrm{z}) \underline{\tilde{U}}(\mathrm{z})+Y_{-}(\mathrm{z}) \mathrm{e}^{j 2 \varphi_{\times}} \underline{\tilde{U}}^{*}\left(\mathrm{z}^{*}\right)=\delta \underline{I}(\mathrm{z})
$$

\section{E. The Fourier-Transform Of The Anisotropic Machine Model}

The signal injection is a strategy based on a repetitive voltage sequence, generally at fixed frequencies, as described in the next section. It is therefore convenient to use the discrete-time Fourier-transform (DTFT) that is found replacing $\mathrm{z}$ by a unitary complex value $\mathrm{e}^{j \omega T_{\mathrm{s}}}$ in the relations, where $\omega \leq \omega_{\mathrm{s}} / 2=\pi / T_{\mathrm{s}}$. As demonstrated in the annexes, the transfer function $D(\mathrm{z})$ linking the mean current to the current difference (10) yields:

$$
D\left(\mathrm{e}^{j \omega T_{\mathrm{s}}}\right)=j \bar{\omega} T_{\mathrm{s}} \quad \text { where } \quad \bar{\omega} \triangleq \tan \left(\omega T_{\mathrm{s}} / 2\right) /\left(T_{\mathrm{s}} / 2\right)
$$

Note that $\bar{\omega}$ tends to $\omega$ when $\omega \ll \omega_{\mathrm{s}}$. Introducing successively (14) in (12), then in (33), the DTFT of positive and negative derivative-admittances are:

$$
\left\{\begin{array}{l}
Y_{+}\left(\mathrm{e}^{j \omega T_{\mathrm{s}}}\right)=T_{\mathrm{s}} \frac{l_{\mathrm{t}+}-j r_{+} / \bar{\omega}}{\left(l_{\mathrm{tx}}-j r_{\mathrm{x}} / \bar{\omega}\right)\left(l_{\mathrm{ty}}-j r_{\mathrm{y}} / \bar{\omega}\right)} \\
Y_{-}\left(\mathrm{e}^{j \omega T_{\mathrm{s}}}\right)=-T_{\mathrm{s}} \frac{l_{\mathrm{t}-}-j r_{-} / \bar{\omega}}{\left(l_{\mathrm{tx}}-j r_{\mathrm{x}} / \bar{\omega}\right)\left(l_{\mathrm{ty}}-j r_{\mathrm{y}} / \bar{\omega}\right)}
\end{array}\right.
$$

This result is not convenient to use in self-sensing operations. By consequence, the resistance is often neglected and these derivative-admittances become very simple as the imaginary and frequency dependent factors vanish:

$$
\left.\begin{array}{l}
r_{\mathrm{x}} \ll \bar{\omega} l_{\mathrm{tx}} \\
r_{\mathrm{y}} \ll \bar{\omega} l_{\mathrm{ty}}
\end{array}\right\} \Rightarrow\left\{\begin{array}{l}
Y_{+}=T_{\mathrm{s}} l_{\mathrm{t}+} /\left(l_{\mathrm{tx}} l_{\mathrm{ty}}\right) \\
Y_{-}=-T_{\mathrm{s}} l_{\mathrm{t}-} /\left(l_{\mathrm{tx}} l_{\mathrm{ty}}\right)
\end{array}\right.
$$

\section{Signal InJeCtion StRATEgY}

\section{A. Principle and Assumptions}

The principle is illustrated in Fig. 3. It consists in the injection of a high-frequency voltage $\underline{\tilde{v}}_{\mathrm{i}}$ computed by the selfsensing operations in addition to the low-frequency voltage $\underline{\tilde{v}}_{c}$ computed by the rotation-drive operations: $\underline{\tilde{v}}=\underline{\tilde{v}}_{\mathrm{c}}+\underline{\tilde{v}}_{\mathrm{i}}$. As a consequence, a high-frequency current response $\underline{i}_{\mathrm{i}}$ is added to the low-frequency current response $\underline{i}_{c}$ controlled by the rotation-drive operations: $\underline{i}=\underline{i}_{\mathrm{c}}+\underline{i}_{\mathrm{i}}$.

In order to prevent or reduce disturbing interactions, the signal-injection operations and the rotation-drive operations should produce signals $\underline{x}_{\mathrm{i}}$ and $\underline{x}_{\mathrm{c}}$ covering separated frequency ranges $\left\{\omega_{\mathrm{c}}\right\}$ and $\left\{\omega_{\mathrm{i}}\right\}$ respectively. In terms of DTFT $\underline{X}=$ $\mathcal{F}\{\underline{x}\}$, the condition is:

$$
\left\{\mid \begin{array}{ll}
\left|\underline{X}_{\mathrm{c}}\left(\mathrm{e}^{j \omega T_{\mathrm{s}}}\right)\right| \ll\left|\underline{X}_{\mathrm{i}}\left(\mathrm{e}^{j \omega T_{\mathrm{s}}}\right)\right| & \text { for } \omega \in\left\{\omega_{\mathrm{i}}\right\} \\
\underline{X}_{\mathrm{c}}\left(\mathrm{e}^{j \omega T_{\mathrm{s}}}\right)|\gg| \underline{X}_{\mathrm{i}}\left(\mathrm{e}^{j \omega T_{\mathrm{s}}}\right) \mid & \text { for } \omega \in\left\{\omega_{\mathrm{c}}\right\}
\end{array}\right.
$$

Note that the frequency content of the PWM is not considered in discrete-time operations and is, by consequence, excluded from the condition (17).

The high-frequency signals inevitably produce a highfrequency torque leading to high-frequency vibrations (that are audible under $20 \mathrm{kHz}$ ) and, by consequence, to a highfrequency back-emf. The mechanical damping effects (due to the inertia plus the frictions of the machine and the coupled load) tend however to increase with the frequency, reducing the high-frequency back-emf to a negligible value. In terms of DTFT of the back-emf $\underline{\tilde{E}}_{\mathrm{PM}}=\mathcal{F}\left\{\underline{\tilde{e}}_{\mathrm{PM}}\right\}$ and of the voltage $\underline{\tilde{V}}=\mathcal{F}\{\underline{\tilde{v}}\}$, this leads to:

$$
\left|\underline{\underline{E}}_{\mathrm{PM}}\left(\mathrm{e}^{j \omega T_{\mathrm{s}}}\right)\right| \ll\left|\underline{\tilde{V}}\left(\mathrm{e}^{j \omega T_{\mathrm{s}}}\right)\right| \quad \text { for } \omega \in\left\{\omega_{\mathrm{i}}\right\}
$$

The back-emf is therefore neglected in self-sensing operations.

\section{B. High-Frequency Anisotropic Model}

Introducing the conditions (17) and (18) in the anisotropic relation (13) yields:

$$
\begin{array}{r}
Y_{+}\left(\mathrm{e}^{j \omega T_{\mathrm{s}}}\right) \tilde{\tilde{V}}_{\mathrm{i}}\left(\mathrm{e}^{j \omega T_{\mathrm{s}}}\right)+Y_{-}\left(\mathrm{e}^{j \omega T_{\mathrm{s}}}\right) \mathrm{e}^{j 2 \varphi_{\mathrm{x}}} \tilde{V}_{\mathrm{i}}^{*}\left(\mathrm{e}^{-j \omega T_{\mathrm{s}}}\right) \\
=\delta \underline{I}_{\mathrm{i}}\left(\mathrm{e}^{j \omega T_{\mathrm{s}}}\right) \quad \text { for } \omega \in\left\{\omega_{\mathrm{i}}\right\}
\end{array}
$$

Note that (19) is valid for any type of high-frequency signal.

In most of the papers dealing with rotating voltage injection, the self-sensing operations are based on the current samples instead of the current-differences. Our choice of the currentdifferences is however justified by the frequency. Using (10) and (14), it is found:

$$
\left|\delta \underline{I}\left(\mathrm{e}^{j \omega T_{\mathrm{s}}}\right)\right|=\left|\bar{\omega} T_{\mathrm{s}}\right| \quad\left|\underline{I}\left(\mathrm{e}^{j \omega T_{\mathrm{s}}}\right)\right|
$$

Assuming a fixed signal injection amplitude, from (4) and (3), it can be shown that the signal-to-noise ratio of the currentdifferences becomes favorable above $\bar{\omega} T_{\mathrm{s}} \geq 2$. Using (14), it corresponds to: $\omega T_{\mathrm{s}} \geq \pi / 2$. 


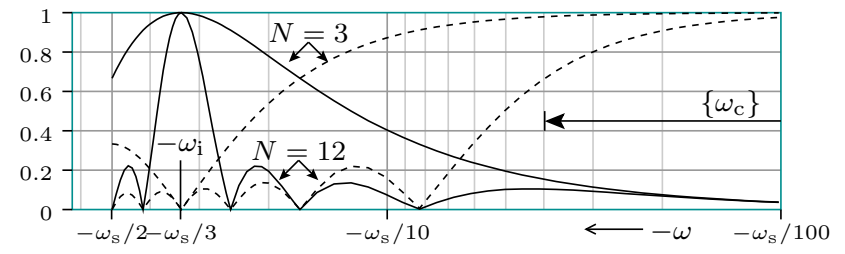

Fig. 4. Filtering characteristics (magnitudes) of the moving average (dashed line) and the moving average shifted at $\omega_{\mathrm{s}} / 3$ (plain line) for $N=3$ and $N=12$, as a function of the signal frequency.

\section{Frequency Response Using Rotating Voltage Injection}

The goal is to obtain a quick estimation of the angle $\varphi_{\mathrm{x}}$ from the model (19). An efficient solution, that does not require initial parameter knowledge, consists to inject a rotating voltage at one frequency $\omega_{i}$. The discrete-time expression of the injected rotating voltage is given as the rotating modulation of an initial voltage space vector $\underline{v}_{\mathrm{i}, o}$ :

$$
\underline{\tilde{v}}_{\mathrm{i}}^{[k]}:=\underline{v}_{\mathrm{i}, o} \mathrm{e}^{j \omega_{\mathrm{i}} k T_{\mathrm{s}}}
$$

The DTFT of this voltage $\tilde{V}_{\mathrm{i}}=\mathcal{F}\left\{\underline{\tilde{v}}_{\mathrm{i}}\right\}$ is null except at $\omega=\omega_{\mathrm{i}}$. In particular, it is null at $\underset{\tilde{V}}{\omega}=-\omega_{\mathrm{i}}$. At $\omega=\omega_{\mathrm{i}}$, it corresponds to its demodulation: $\underline{\tilde{V}}_{\mathrm{i}}\left(\mathrm{e}^{j \omega_{\mathrm{i}} T_{\mathrm{s}}}\right)=\underline{v}_{\mathrm{i}, o}$. Thus (19) at $\omega=-\omega_{\mathrm{i}}$ yields:

$$
Y_{-}\left(\mathrm{e}^{-j \omega_{\mathrm{i}} T_{\mathrm{s}}}\right) \mathrm{e}^{j 2 \varphi_{\mathrm{x}}}=\delta \underline{I}_{\mathrm{i}}\left(\mathrm{e}^{-j \omega_{\mathrm{i}} T_{\mathrm{s}}}\right) / \underline{v}_{\mathrm{i}, o}
$$

The DTFT of the current difference at $-\omega_{\mathrm{i}}$ can be computed as the result of a low-pass filter (LPF) applied to the demodulated signal, keeping only the constant component:

$$
\delta \underline{I}_{\mathrm{i}}\left(\mathrm{e}^{-j \omega_{\mathrm{i}} T_{\mathrm{s}}}\right):=\operatorname{LPF}\left(\delta \underline{i}_{\mathrm{i}}^{[k]} \mathrm{e}^{j \omega_{\mathrm{i}} k T_{\mathrm{s}}}\right)
$$

Considering the condition (17), the low frequency $\delta \underline{i}_{\mathrm{c}}$ should be removed in this operation and $\delta \underline{i}$ can be used instead of $\delta \underline{i}_{\mathrm{i}}$ in (23). Even if the LPF is not ideal, the low frequency content of $\delta \underline{i}_{\mathrm{c}}$ should however be reduced using current differences, since the amplitude $|\delta \underline{I}|$ decreases at lower frequencies, as shown by (20). This is another strong benefit compared to operations based on current samples. Dividing (23) by $\underline{v}_{\mathrm{i}, o}$ and using (21), (22) can be computed as follows:

$$
Y_{-}\left(\mathrm{e}^{-j \omega_{\mathrm{i}} T_{\mathrm{s}}}\right) \mathrm{e}^{j 2 \varphi_{\mathrm{x}}}=\operatorname{LPF}\left(\delta \underline{i}^{[k]} / \underline{\tilde{v}}_{\mathrm{i}}^{*[k]}\right)
$$

The angle $\varphi_{\mathrm{x}}$ is easily extracted from that result. The challenge is now to implement the LPF.

Note that some papers use pre-filtering with band-pass (BPF) or band-stop filters on the current signal in order to extract the signal-injection current response before the demodulation [11], [19], [23], [26], [27], [36], [44], [45], [52], [56], [60], [61]: $\underline{i}_{\mathrm{i}}=\operatorname{BPF}(\underline{i})$. This is however not required since (24) naturally removes the frequency content outside $-\omega_{\mathrm{i}}$. Moreover, the fact to use operations directly based on the ratio between the current and the high-frequency voltage removes lagging problems [23], [56].

\section{Filtering Operations}

We propose LPF operations based on the moving average, that is a finite impulse response (FIR) filter defined as the mean of the $N$ previous discrete-time values $\underline{x}$, computed every sampling period $k$ [59]:

$$
\operatorname{LPF}^{[k]}(\underline{x}):=\frac{1}{N} \sum_{n=0}^{N-1} \underline{x}^{[k-n]}
$$

Its characteristic for the negative frequencies is illustrated in Fig. 4 with dashed lines for the case $N=3$ and $N=12$.

Assume that the high-frequency $\omega_{\mathrm{i}}$ of the injected signals is an integer fraction $N_{\mathrm{i}} \geq 3$ of the sampling frequency $\omega_{\mathrm{s}}$ :

$$
\omega_{\mathrm{i}}=\omega_{\mathrm{s}} / N_{\mathrm{i}} \quad \Rightarrow \quad \omega_{\mathrm{i}} T_{\mathrm{s}}=2 \pi / N_{\mathrm{i}}
$$

The moving average (25) can then be used as a LPF for the operation (24), selecting an integer multiple $N$ of $N_{\mathrm{i}}$. Considering the case $N_{\mathrm{i}}=3$, the characteristic of the moving averages shifted around $-\omega_{\mathrm{i}}=-\omega_{\mathrm{s}} / 3$ is illustrated in Fig. 4 with plain lines for $N=N_{\mathrm{i}}=3$ and $N=4 \times N_{\mathrm{i}}=12$. The choice of $N$ depends on the expanse of the low-frequency range $\left\{\omega_{\mathrm{c}}\right\}$ to be removed. However, assuming that $\omega_{\mathrm{i}}$ is much higher than $\left\{\omega_{\mathrm{c}}\right\}$, a higher $N$ does not strongly improve the attenuation characteristic at low frequencies, while it requires more computational power.

Until now, we assumed a constant anisotropy angle $\varphi_{\mathrm{x}}$ during the operations. In practice however, this angle $\omega_{\mathrm{x}}=$ $d \varphi_{\mathrm{x}} / d t$ varies due to the machine rotation and to possible harmonics in the anisotropy variations, introducing a rotating term applied to the current. This leads to a spectrum shift of $2 \omega_{\mathrm{x}}$ since the DTFT becomes:

$$
\mathcal{F}\left\{\mathrm{e}^{j 2 \omega_{\mathrm{x}} t^{[k]}} \delta \underline{i}^{*[k]}\right\}=\delta \underline{I}^{*}\left(\mathrm{e}^{-j\left(\omega-2 \omega_{\mathrm{x}}\right) T_{\mathrm{s}}}\right)
$$

It is negligible if $\left|2 \omega_{\mathrm{x}}\right| \ll\left|\omega_{\mathrm{i}}\right|$, but this condition must be checked. Other spectrum dispersions are due to possible variations in the parameter values. The choice of $N$ also depends on this spectrum dispersions around $-\omega_{\mathrm{i}}$. Higher $N$, higher the risk to filter beside the high-frequency current response. We propose therefore to use to lowest $N=N_{\mathrm{i}}$ for the operations (24).

Apart from this, the moving average can also be used to remove the high-frequency current component in the samples $\underline{i}\left(t^{[k]}\right)$ for the rotation-drive operations:

$$
\operatorname{LPF}\left(\underline{i}_{\mathrm{i}}\right)=0 \Rightarrow \operatorname{LPF}\left(\underline{i}_{\mathrm{c}}\right)=\operatorname{LPF}(\underline{i})
$$

If the controller bandwidth is much smaller than $\omega_{\mathrm{i}}$ however, the filtering becomes unnecessary [56].

In many papers, operations are based on infinite impulse response (IIR) filters [11], [12], [33], [44], [45], [52], [56], [61]-[63]. The comparison between IIR and FIR filters would require further analysis, but apriori, the moving average provides a simple solution with good filtering characteristics and with good phase linearity. Moreover, the stabilization time of the FIR is not greater than $N$ sampling periods, while it can be much longer with IIR filters for the same bandwidth.

\section{E. Issue Regarding The PWM-VSI}

We assume that the voltages are not measured but the command voltage is used instead. Dead-times in the pulse-width modulation (PWM) and voltage drops at the semiconductors 
of the voltage-source inverter (VSI) are common nonlinearities that must be managed. They can generally be linearized and compensated assuming fixed phase current flows [4], [31], [36], [44]. Moreover, their frequency content is mainly present in the low-frequencies.

When a phase current crosses zero however, non compensable dead-times and voltage drops discontinuities occur, referred to as zero-crossing clamping phenomenons. Even small, they may lead to significant estimation errors [36], [52], [64]. The smaller $N_{\mathrm{i}}$ however, the smaller the number of estimations affected by the zero-crossing nonlinearity and better is the robustness of the self-sensing regarding the inverter nonlinearities. This is valid also regarding any other interruption in the measurements or in the signal injection.

\section{F. Position Extraction}

As it is widely assumed in the literature, if the resistance impact is negligible compared to the inductance, the positive $Y_{+}$and negative $Y_{-}$derivative-admittances are strictly real values (16). Using (24), the angle $\mathrm{e}^{j 2 \varphi_{\mathrm{x}}}$ is then easily extracted by:

$$
\hat{\varphi}_{\mathrm{x}}=\frac{\angle\left(-\operatorname{LPF}\left(\delta \underline{i} / \underline{\tilde{v}}_{\mathrm{i}}^{*}\right)\right)}{2}
$$

where $\angle$ denotes the complex argument. Note that there is an ambiguity of $\pi$ on $\hat{\varphi}_{\mathrm{x}}$ that is inherent to this method. This ambiguity can be initially removed by tracking differences of the incremental inductance along opposite magnetizing directions (positive and negative values along the d-axis), injecting current oscillations of large amplitudes and assuming that the inductance differences is larger than the noise [4], [5], [61], [62], [65]. The ambiguity may also be removed at higher speed using back-emf observation [47].

In practice however, the resistance is not always negligible, and $Y_{-}$is not strictly real, leading to angle estimation errors. Using (29), this error is the half complex argument of $Y$ - given in $(15)$ :

$$
\begin{aligned}
\hat{\varphi}_{\mathrm{x}}-\varphi_{\mathrm{x}} & =\angle\left(-Y_{-}\left(\mathrm{e}^{-j \omega_{\mathrm{i}} T_{\mathrm{s}}}\right)\right) / 2=\left(\angle\left(l_{\mathrm{t}-}+j r_{-} / \bar{\omega}_{\mathrm{i}}\right)\right. \\
& \left.-\angle\left(l_{\mathrm{tx}}+j r_{\mathrm{x}} / \bar{\omega}_{\mathrm{i}}\right)-\angle\left(l_{\mathrm{ty}}+j r_{\mathrm{y}} / \bar{\omega}_{\mathrm{i}}\right)\right) / 2
\end{aligned}
$$

\section{G. Discussion On The Injected Amplitude And Frequency}

The discussion is based on a fixed high-frequency current amplitude. The selection of the amplitude is a compromise: on one hand, it should be the smallest possible in order to reduce the resistive loss, the vibrations and to limit the problems of possible zero-crossing nonlinearities. On the other hand, the amplitude must be high enough in order to satisfy the condition (17) and in order to provide a good signal-to-noise ratio.

The higher the signal injection frequency, the higher the required injected voltage amplitude, assuming a fixed current response amplitude. This reduces the range of voltage allowable for the rotation-drive operations. Moreover, the audible nuisance increases with the frequency. Assuming that these issues are managed, using higher frequencies however present significant benefits. According to the discussed aspects, they are:
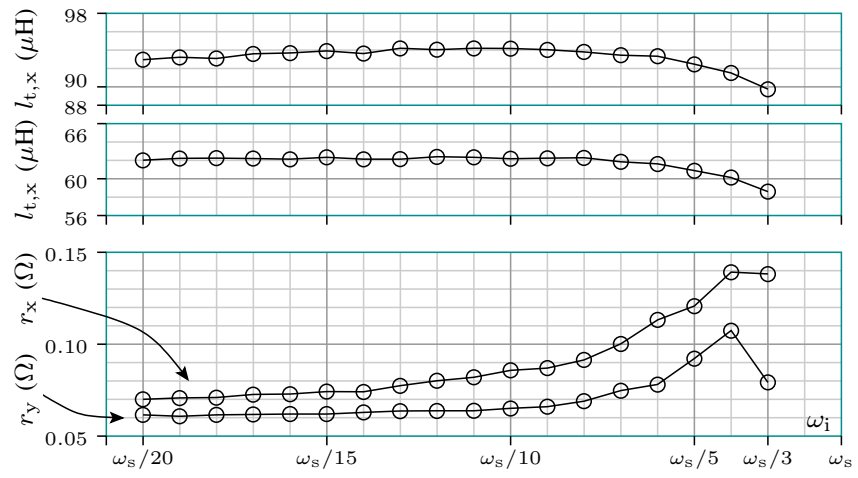

Fig. 5. Apparent resistances and inductances of the experimental BLDC machine identified at different frequencies $\omega_{\mathrm{i}}$, assuming $\nu_{\mathrm{s}}=$ $10 \mathrm{kHz}$, with $\omega_{\mathrm{s}}=2 \pi \nu_{\mathrm{s}}$.

1) reduction of frequency interactions (18) and decrease of the back-emf influence (17);

2) low computation requirements, since the computation steps of the moving average (25) is proportional to $N_{\mathrm{i}}$;

3) low settling time at initialization and restart, due the stabilization time of only $N_{\mathrm{i}}$ sampling periods;

4) robustness regarding inverter nonlinearities and other interruptions.

It is also beneficial regarding the resistance impact (30), assuming that $r_{ \pm} / \bar{\omega}_{\mathrm{i}}$ decreases with the frequency $\omega_{\mathrm{i}}$. Note however that the contribution of Eddy-currents increases with the signal frequency [27], [32], [34], [54], [55] and augment the apparent value of the resistances. This issue is analyzed experimentally hereafter. As a conclusion, the optimum frequency is the maximum satisfying (26) and defining a rotating space vector: $N_{\mathrm{i}}=3$.

\section{Analysis With Experimental Cases}

\section{A. Experimental Machine And Test Setup}

The experimental machine is a three-phase $3 \mathrm{~kW}$ in-wheel brushless-DC (BLDC) motor with 14 pairs of surface-mounted permanent-magnets in an outer rotor. It is developed by Technicréa, France, for the propulsion of small vehicles. Details on the design of similar machines can be found in [66]. The rated stator current in the machine is $134 \mathrm{~A}$ and the rated rotation speed is $500 \mathrm{rpm}$. The machine is fed with an IGBT voltage-source inverter (VSI) supplied by a rated $v_{\mathrm{dc}}=50 \mathrm{~V}$ DC-voltage. The PWM generator works at $\nu_{\mathrm{s}}=10 \mathrm{kHz}$. The resolution of the current measurements is $0.244 \mathrm{~A}$. Its apparent parameters have been estimated at different frequencies using small pulsating signals along the $\mathrm{x}$ and $\mathrm{y}$-axes on a standstill unlocked machine. Results are shown in Fig. 5. As expected, the frequency influence the apparent value of the resistances and, a lesser extent, of the inductances.

\section{B. Errors Due To The Resistance}

Fig. 6 shows the theoretical error (30) due to the resistance for different signal injection frequencies with respect to the sampling frequency $\omega_{\mathrm{s}}=2 \pi \nu_{\mathrm{s}}$. The circles, joined by plain lines, correspond to the error with our experimental BLDC 


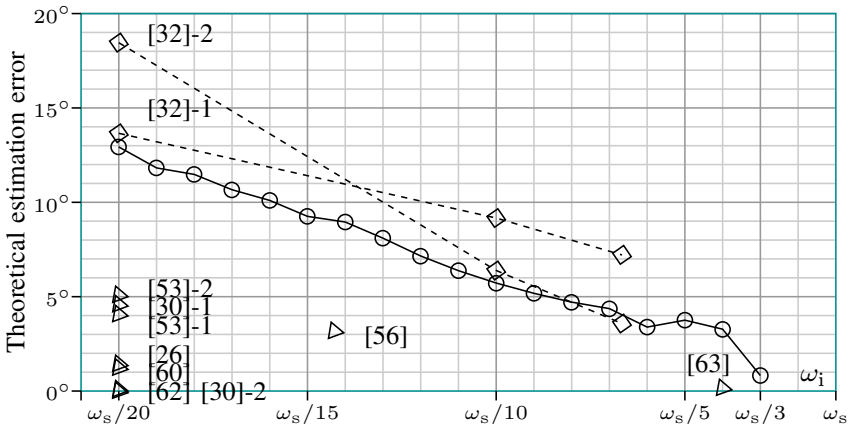

Fig. 6. Theoretical estimation errors $\left|\hat{\varphi}_{\mathrm{x}}-\varphi_{\mathrm{x}}\right|$ in experimental cases.

TABLE I

PARAMETERS OF SOME MACHINES FOUND IN THE LITERATURE.

\begin{tabular}{|c|c|c|c|}
\hline & $\nu_{\mathrm{i}}(\mathrm{Hz})$ & {$\left[r_{\mathrm{y}}-r_{\mathrm{x}}\right](\Omega)^{(*)}$} & {$\left[l_{\mathrm{t}, \mathrm{y}}-l_{\mathrm{t}, \mathrm{x}}\right](\mathrm{H})^{(* *)}$} \\
\hline \hline$[32]-1$ & $0.5 \mathrm{k}$ & {$[0.404-0.635]$} & {$[2.33-3.61] \mathrm{m}$} \\
\hline$[32]-1$ & $1 \mathrm{k}$ & {$[1.339-1.959]$} & {$[2.33-3.61] \mathrm{m}$} \\
\hline$[32]-1$ & $1.5 \mathrm{k}$ & {$[2.601-4.431]$} & {$[2.33-3.61] \mathrm{m}$} \\
\hline$[32]-2$ & $0.5 \mathrm{k}$ & {$[0.259-0.436]$} & {$[2.17-2.83] \mathrm{m}$} \\
\hline$[32]-2$ & $1 \mathrm{k}$ & {$[0.765-1.385]$} & {$[2.17-2.83] \mathrm{m}$} \\
\hline$[32]-2$ & $1.5 \mathrm{k}$ & {$[1.48-2.791]$} & {$[2.17-2.83] \mathrm{m}$} \\
\hline$[63]$ & $2.5 \mathrm{k}$ & 0.15 & {$[2.5-3.1] \mathrm{m}$} \\
\hline$[56]$ & 700 & 1.5 & {$[5.15-7.35] \mathrm{m}$} \\
\hline$[60]$ & 500 & 0.0103 & {$[101-306] \mu$} \\
\hline$[26]$ & 500 & 1.4 & {$[10-76] \mathrm{m}$} \\
\hline$[53]-1$ & 500 & 2.2 & {$[6.5-19.69] \mathrm{m}$} \\
\hline$[53]-2$ & 500 & 2.875 & {$[8.5-12.75] \mathrm{m}$} \\
\hline$[62]$ & 500 & $8.4 \mathrm{~m}$ & {$[100-300] \mu$} \\
\hline$[30]-1$ & 500 & {$[1.87-1.96]$} & {$[7.5-9.4] \mathrm{m}$} \\
\hline$[30]-2$ & 500 & {$[0.76-0.88]$} & {$[420-440] \mu$} \\
\hline Af & \multicolumn{3}{|c|}{ machines are permanent-magnets, except [26] that is a switched }
\end{tabular}

Aluctance machine. These parameters must be taken with care and as information only. ${ }^{*}$ If the high-frequency resistance is not mentioned, the DC resistance is taken instead. ${ }^{(* *)}$ We take the inductances corresponding to the lowest load. The digital sampling frequency is $\nu_{\mathrm{s}}=10 \mathrm{kHz}$ for all drives, except in [26], [53] where this frequency is assumed because not specified. Note that $\omega=2 \pi \nu$.

machine, using the parameters of Fig. 5. It is observed that, even if the apparent resistance tends to increase with the frequency, its relative impact is divided by $\bar{\omega}_{\mathrm{i}}$ and tends to decrease. This tends to confirm the benefits of using the highest frequency.

Results using the parameters of some machines found in the literature are shown by diamonds and triangles. The parameters can be found in TABLE I. If there is more than one machine in one reference, the reference is followed by a numbering for each machine. In [32], parameters of two machines are given at three different frequencies. The corresponding errors are mentioned in Fig. 6 by diamonds joined by dashed lines. A decrease of the resistance impact is also observed. The other machines are mentioned by triangles. We can see that many papers chose a frequency at $\nu_{\mathrm{i}}=\nu_{\mathrm{s}} / 20=500 \mathrm{~Hz}$. Even if the error is typically not much larger than $5^{\circ}$, using higher frequencies could possibly further reduce the resistance impact.

\section{EXPERIMENTS}

\section{A. Measurements And Figures}

Experiments are performed on the experimental BLDC machine described above. Having 14 pole-pairs, its rated speed
$500 \mathrm{rpm}$ corresponds to a rotation frequency of $14 * 500 / 60=$ $116 \mathrm{~Hz}$. This indicates the lower limit for the signal injection operations. The current controller bandwidth is around $400 \mathrm{~Hz}$. A speed control is performed for the experiments, with a rather low bandwidth around $10 \mathrm{~Hz}$. Note that the BLDC motors are generally not controlled in speed, but in torque only. The estimated position is filtered through a third order observer, with a $62.6 \mathrm{~Hz}$ bandwidth, before it is used in the vector control of the rotation-drive. This observer also provides the speed estimation.

From the top to the bottom, Fig. 7, Fig. 8 and Fig. 9 are organized as follows: 1) a graph of the current samples of the first phase containing both high and low-frequency content (gray dots) and the filtered currents for the normaldrive operations (black dots); 2) the rotation speed (electrical frequency) measured by an external encoder (dashed lines) and the anisotropy speed estimated by the observer (black dots); 3) the rotor-PM angle (electrical degree) measured by an external encoder (dashed lines) and the estimated anisotropy angle using (29) (black dots); 4) the error (electrical degree) between the estimated angle and the rotor-PM angle; 5) the frequency spectrum $\left|\underline{I}\left(\mathrm{e}^{j \omega T_{\mathrm{s}}}\right)\right|$ of the current samples. As discussed in Section III, the position information is contained in the negative frequency $\nu=-\nu_{\mathrm{i}}$.

\section{B. Disturbance Sources}

The zero-clamping inverter nonlinearity is very annoying in this type of machine: when a phase current crosses zero, the position is lost. In order to prevent this drawback, a current offset is added to the instruction to maintain a margin with respect to the zero-crossing phase lines. This offset is chosen in order to minimize its impact on the torque. As a consequence of the offset, the low-frequency current signal behaviour is far from a sinusoidal signal and the current instruction regularly jumps across the zero-crossing phase lines. This is clearly visible on the current signals. Since the position is lost, the self-sensing operations (but not the signal injection) are interrupted during the jumps. The lower the injected signal frequency, the longer the duration of the interruption. More details can be found in [67].

Oscillations in the estimated anisotropy angle, inherited by the speed estimation, are partly due to significant harmonics in the machine (harmonics in the air-gap magnetic field and in the winding distributions). No compensation is performed here. More details can be found in [24].

\section{Results}

The two first experiments compare the case $N_{\mathrm{i}}=20$, i.e. $\nu_{\mathrm{i}}=500 \mathrm{~Hz}$, in Fig. 7 with the case $N_{\mathrm{i}}=3$, i.e. $\nu_{\mathrm{i}}=3333 \mathrm{~Hz}$, in Fig. 8, for low-speed drives at $5 \mathrm{~Hz}$ that is $4.3 \%$ the rated speed. The voltage is chosen such that the peak values of the high-frequency current are equal in both cases, around $2 \mathrm{~A}$ that is $1.5 \%$ the rated current. For each case respectively it is $0.36 \mathrm{~V}$, i.e. $1.4 \%$ of $v_{\mathrm{dc}} / 2$, and $2 \mathrm{~V}$, i.e. $8 \%$ of $v_{\mathrm{dc}} / 2$. The drive operations are based on the encoder measurements and not on the estimated position in order to strictly assess the quality of the estimation and prevent feedback effects. The 


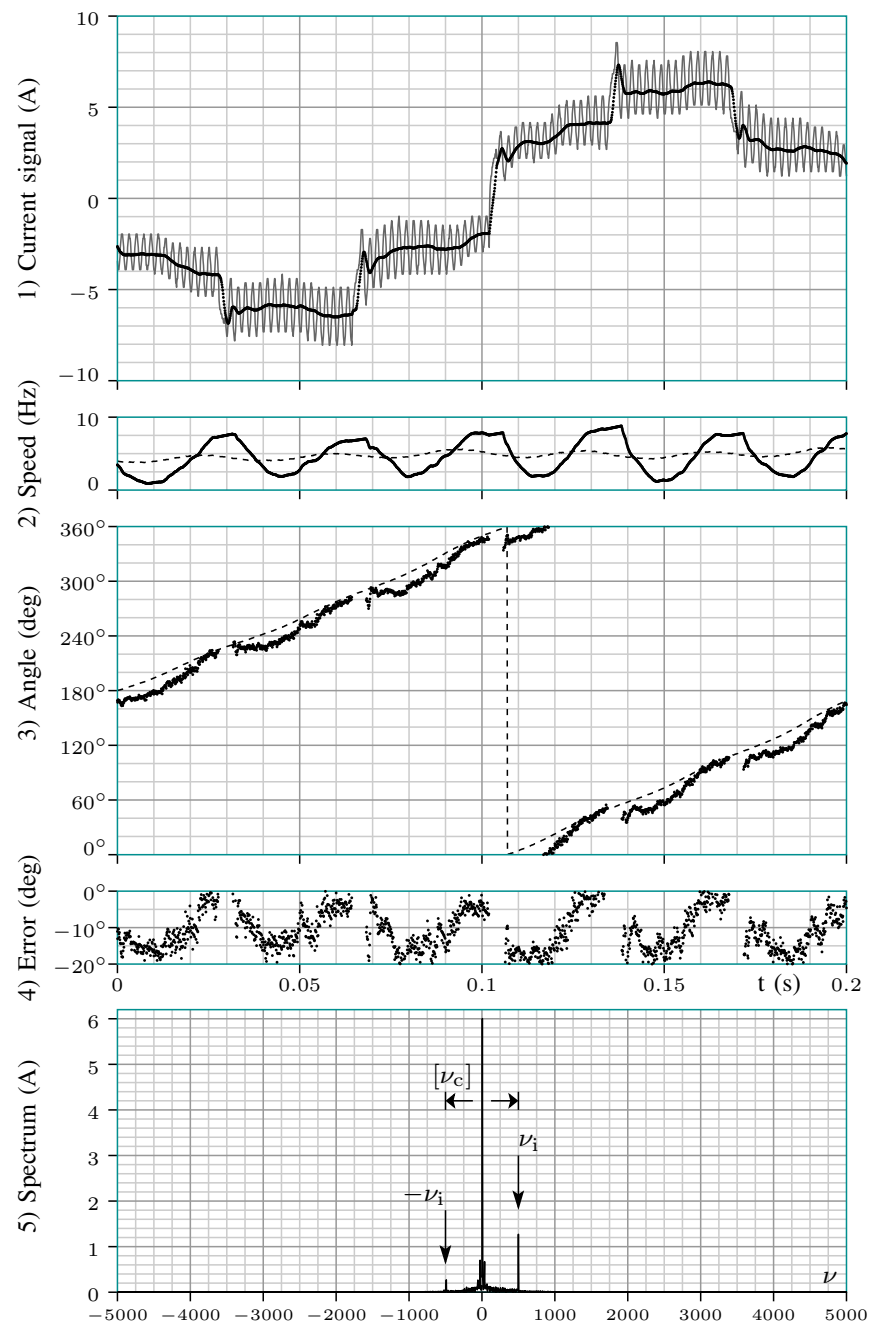

Fig. 7. Experiments with a $0.36 \mathrm{~V}$ rotating voltage injection and $N_{\mathrm{i}}=20$, i.e. $\nu_{\mathrm{i}}=500 \mathrm{~Hz}$. Speed instruction at $5 \mathrm{~Hz}$.

errors are around $-10^{\circ}$ for $N_{\mathrm{i}}=20$ and close to zero for $N_{\mathrm{i}}=3$, as theoretically predicted. An important problem with $N_{\mathrm{i}}=20$ is the interruption due to the zero-crossing, that becomes relatively long compared to the rotation period at higher speeds. The spectra illustrate the better frequency separation between signal injection and rotation-drive signals in the case of $N_{\mathrm{i}}=3$.

The third experiment Fig. 9 shows the result of selfsensing operations, where the estimated position is used by the vector control. The experiment starts at standstill with the speed instruction step of $60 \mathrm{~Hz}$ at $t=0$, that is $51.7 \%$ of the rated speed. Note that $0.2 \mathrm{~s}$ is quite short for such an acceleration in vehicle applications. At $t=0.02 \mathrm{~s}$, larger errors on the position and the speed (negative) are observed, due to a phase current zero-crossing (inverter nonlinearity) that is not perfectly avoided. Such errors are repeated, especially at higher speeds. Above $60 \mathrm{~Hz}$, the position estimation is strongly degraded because of the zero-crossings and the lower quantity of information, but this speed limitation is not inherent to the self-sensing. A clear spectrum dispersion is observed at $-\nu_{\mathrm{i}}$. Despite the zero-crossing effects, the harmonic oscillations and the spectrum dispersion, these results are very satisfying
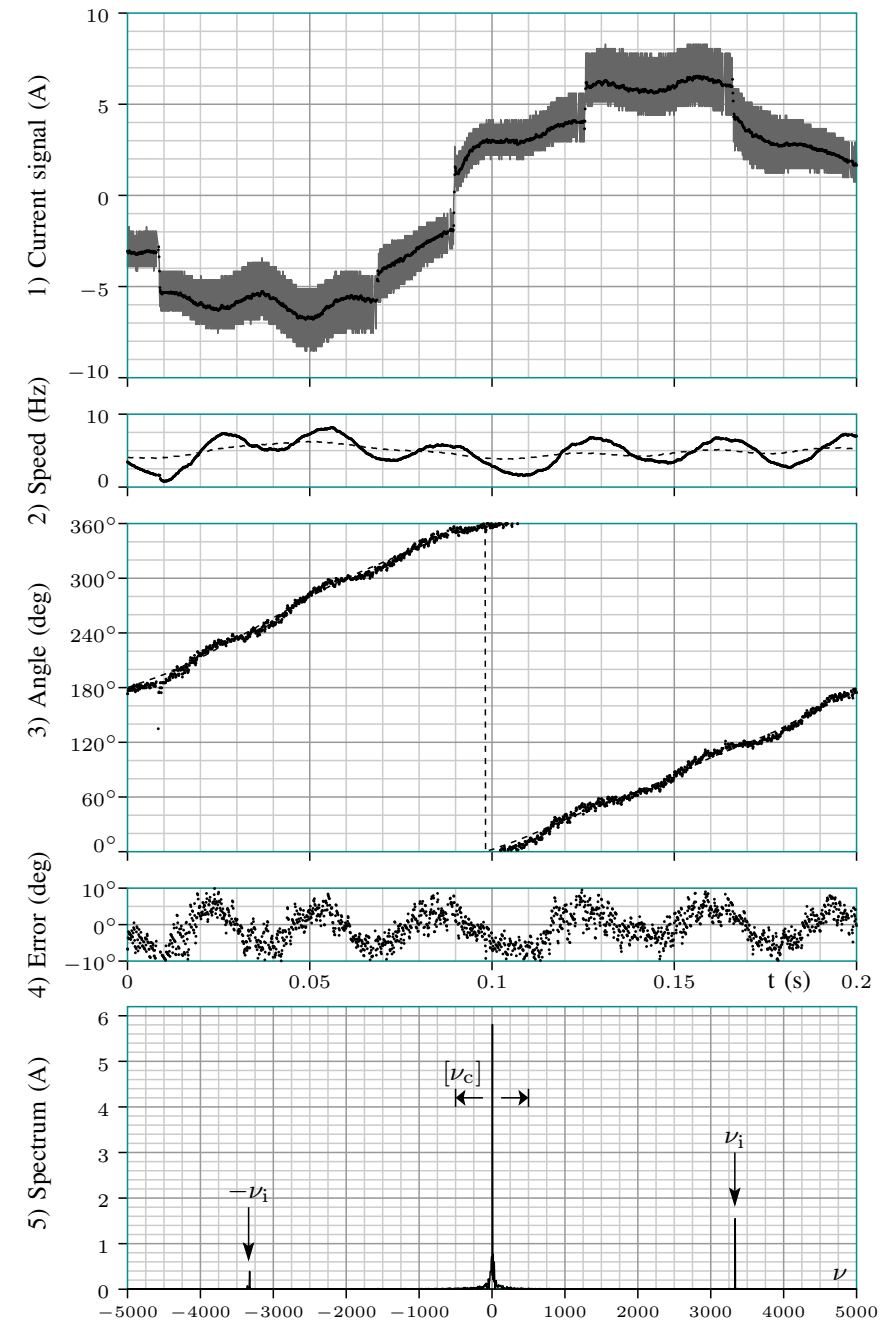

Fig. 8. Experiments with a $2 \mathrm{~V}$ rotating voltage injection and $N_{\mathrm{i}}=3$, i.e. $\nu_{\mathrm{i}}=3333 \mathrm{~Hz}$. Speed instruction at $5 \mathrm{~Hz}$.

for that type of machine. Note that the obtained resolution is much better than the one provided by the hall-effect sensors traditionally used with BLDC machines.

\section{CONCLUSIONS}

We discussed several benefits using a discrete-time model, the current-difference response instead of the current samples, a moving average for the filtering operations and the highest possible frequency for the signal injection, in order to estimate the position in an optimal way. Based on these considerations, we conclude that the optimal frequency for a rotating voltage injection is one third of the sampling frequency, valid from standstill up to the large range of rotation speeds.

\section{ANNEXES}

\section{A. Inversion Of The Anisotropic Relation}

Since positive and negative parameters are reals defined by (8), the only imaginary values in the integral-impedances (12) are z. Thus: $Z_{ \pm}^{*}\left(\mathrm{z}^{*}\right)=Z_{ \pm}(\mathrm{z})$. The complex conjugate $\underline{I}^{*}\left(\mathrm{z}^{*}\right)$ computed from the left member of (11) yields then:

$$
\delta \underline{I}^{*}\left(\mathrm{z}^{*}\right)=\left(\underline{\tilde{U}}^{*}\left(\mathrm{z}^{*}\right)-Z_{-}(\mathrm{z}) \mathrm{e}^{-j 2 \varphi_{\mathrm{x}}} \delta \underline{I}(\mathrm{z})\right) / Z_{+}(\mathrm{z})
$$



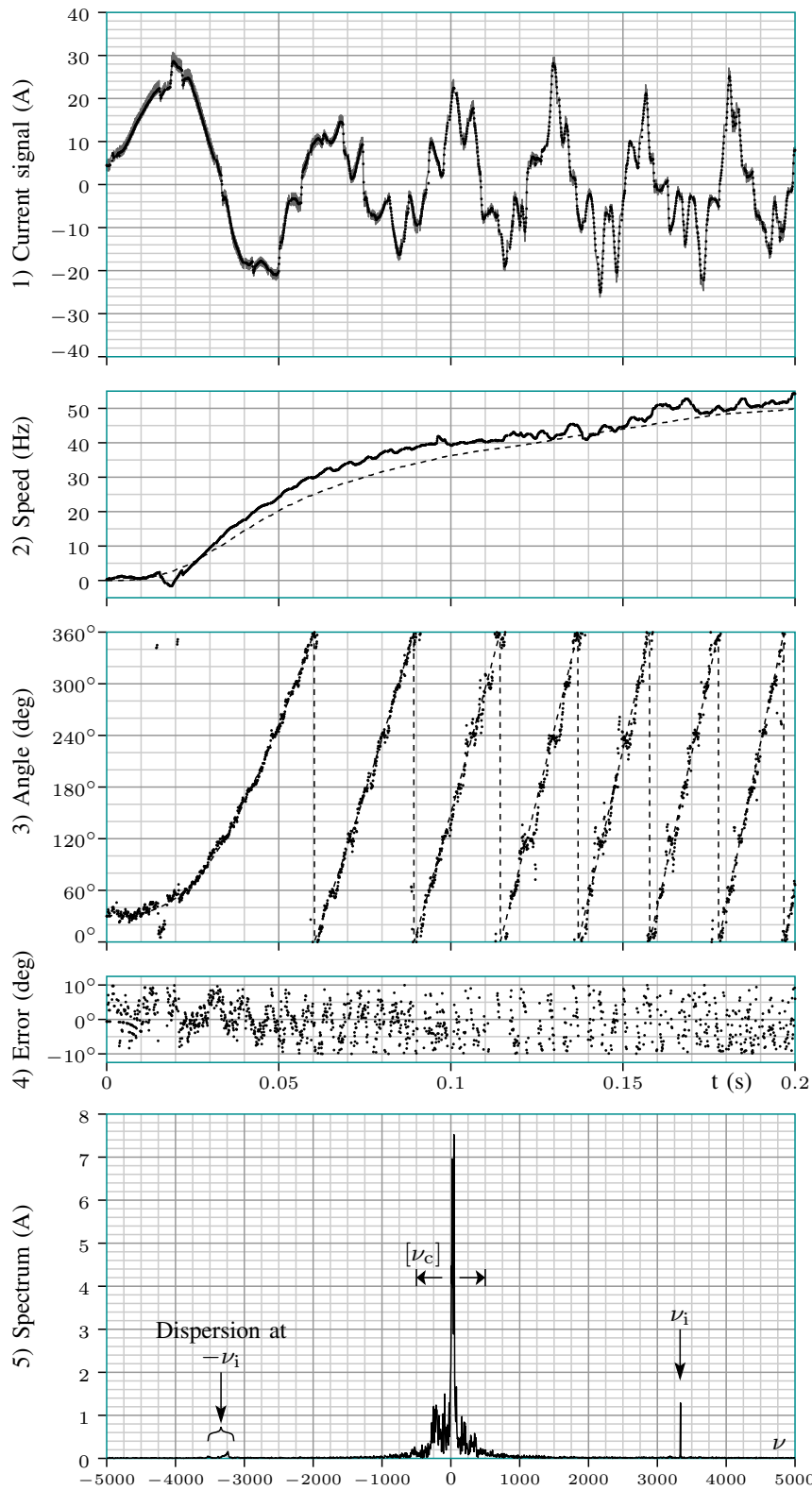

Fig. 9. Experiments with a $2 \mathrm{~V}$ rotating voltage injection and $N_{\mathrm{i}}=3$. Step instruction from standstill to $60 \mathrm{~Hz}$.

Replacing $\underline{I}^{*}\left(\mathrm{z}^{*}\right)$ back in (11) yields: $\quad Z_{+}(\mathrm{z}) \underline{\tilde{U}}(\mathrm{z})$

$$
=\left(Z_{+}^{2}(\mathrm{z})-Z_{-}^{2}(\mathrm{z})\right) \delta \underline{I}(\mathrm{z})+Z_{-}(\mathrm{z}) \mathrm{e}^{j 2 \varphi_{x}} \underline{\tilde{U}}^{*}\left(\mathrm{z}^{*}\right)
$$

Using (8): $Z_{+}^{2}(\mathrm{z})-Z_{-}^{2}(\mathrm{z})=Z_{\mathrm{x}}(\mathrm{z}) Z_{\mathrm{y}}(\mathrm{z})$. Then (13) is found if we define the positive and negative derivative-admittance as:

$$
\left\{\begin{array}{l}
Y_{+}(\mathrm{z}) \triangleq Z_{+}(\mathrm{z}) / Z_{\mathrm{x}}(\mathrm{z}) Z_{\mathrm{y}}(\mathrm{z}) \\
Y_{-}(\mathrm{z}) \triangleq-Z_{-}(\mathrm{z}) / Z_{\mathrm{x}}(\mathrm{z}) Z_{\mathrm{y}}(\mathrm{z})
\end{array}\right.
$$

\section{B. Computation of $D\left(\mathrm{e}^{j \omega T_{\mathrm{s}}}\right)$}

Replacing z by $\mathrm{e}^{j \xi}$ where $\xi=\omega T_{\mathrm{s}}$, (10) yields (14):

$$
\frac{D\left(\mathrm{e}^{j \xi}\right)}{2}=\frac{1-\mathrm{e}^{-j \xi}}{1+\mathrm{e}^{-j \xi}}=\frac{\mathrm{e}^{-j \xi / 2}-\mathrm{e}^{-j \xi / 2}}{\mathrm{e}^{-j \xi / 2}+\mathrm{e}^{-j \xi / 2}}=\frac{\sin (\xi / 2)}{\cos (\xi / 2)}
$$

\section{REFERENCES}

[1] J. Finch and D. Giaouris, "Controlled ac electrical drives," IEEE Transactions on Industrial Electronics, vol. 55, pp. 481 - 491, Feb. 2008.

[2] I. Boldea, "Control issues in adjustable speed drives," IEEE Industrial Electronics Magazine, vol. 2, pp. 32 - 50, Sept. 2008.

[3] M. Pacas, "Sensorless drives in industrial applications," IEEE Industrial Electronics Magazine, vol. 5, pp. 16 - 23, June 2011.

[4] J. Holtz, "Sensorless control of induction machines - with or without signal injection ?," IEEE Transactions on Industrial Electronics, vol. 53, pp. 7 - 30, Feb. 2005.

[5] P. Acarnley and J. Watson, "Review of position-sensorless operation of brushless permanent-magnet machines," IEEE Transactions on Industrial Electronics, vol. 53, pp. 352 - 362, Apr. 2006

[6] E. Robeischl and M. Schroedl, "Optimized inform measurement sequence for sensorless pm synchronous motor drives with respect to minimum current distortion," IEEE Transactions on Industry Applications, vol. 40, pp. 591 - 598, Mar. 2004.

[7] S. Bolognani, S. Calligaro, R. Petrella, and M. Sterpellone, "Sensorless control for ipmsm using pwm excitation: Analytical developments and implementation issues," in Symposium on Sensorless Control for Electrical Drives (SLED), pp. 64 - 73, Sept. 2011.

[8] R. Leidhold, "Position sensorless control of pm synchronous motors based on zero-sequence carrier injection," IEEE Transactions on Industrial Electronics, vol. 58, pp. 5371 - 5379, Dec. 2011.

[9] C. Wang and L. Xu, "A novel approach for sensorless control of pm machines down to zero speed without signal injection or special pwm technique," IEEE Transactions on Power Electronics, vol. 19, pp. 1601 - 1607, Nov. 2004.

[10] F. De Belie and J. Melkebeek, "Seamless integration of a low-speed position estimator for ipmsm in a current-controlled voltage-source inverter," in Symposium on Sensorless Control for Electrical Drives (SLED), pp. $50-55$, July 2010.

[11] S. Kim, J.-I. Ha, and S.-K. Sul, "Pwm switching frequency signal injection sensorless method in ipmsm," IEEE Transactions on Industry Applications, vol. 48, pp. 1576 - 1587, Sept. 2012.

[12] P. Garcia, F. Briz, M. Degner, and D. Diaz-Reigosa, "Accuracy, bandwidth, and stability limits of carrier-signal-injection-based sensorless control methods," IEEE Transactions on Industry Applications, vol. 43 , pp. 990 - 1000, July 2007.

[13] I. Boldea, M. Paicu, and G.-D. Andreescu, "Active flux concept for motion-sensorless unified ac drives," IEEE Transactions on Power Electronics, vol. 23, pp. 2612 -2618, Sept. 2008.

[14] M. Tursini, C. Olivieri, and L. D. Leonardo, "Analysis of phase-detection algorithms for back-emf-based sensorless startegies through real-time simulations," in Sensorless Control for Electrical Drives (SLED), pp. 129 - 137, Sept. 2011

[15] J. Holtz and J. Juliet, "Sensorless acquisition of the rotor position angle of induction motors with arbitrary stator windings," IEEE Transactions on Industry Applications, vol. 41, pp. 1675 - 1682, Nov. 2005.

[16] R. Cardenas, R. Pena, J. Proboste, G. Asher, and J. Clare, "Mras observer for sensorless control of standalone doubly fed induction generators," IEEE Transactions on Energy Conversion, vol. 20, pp. 710 - 718, Dec. 2005.

[17] Y. Shi, K. Sun, L. Huang, and Y. Li, "On-line identification of permanent magnet flux based on extended kalman filter for ipmsm drive with position sensorless control," IEEE Transactions on Industrial Electronics, vol. PP, no. 99, p. 1, 2011

[18] J. Melkebeek, "Small signal dynamic modelling of saturated synchronous machines," in International Conference on Electrical Machines (ICEM), no. 2, pp. 447 - 450, Sept. 1984.

[19] A. Consoli, G. Scarcella, and A. Testa, "Sensorless control of ac motors at zero speed," in International Symposium on Industrial Electronics (ISIE), vol. 1, pp. 373 - 379, 1999.

[20] F. Briz, M. Degner, P. Garcia, and R. Lorenz, "Comparison of saliencybased sensorless control techniques for ac machines," IEEE Transactions on Industry Applications, vol. 40, pp. 1107 - 1115, July 2004.

[21] F. De Belie, J. Melkebeek, L. Vandevelde, R. Boel, K. Geldhof, and T. Vyncke, "A nonlinear model for synchronous machines to describe high-frequency signal based position estimators," in IEEE International Conference on Electric Machines and Drives, pp. 696 - 703, May 2005.

[22] P. Guglielmi, M. Pastorelli, and A. Vagati, "Cross-saturation effects in ipm motors and related impact on sensorless control," IEEE Transactions on Industry Applications, vol. 42, pp. 1516 - 1522, Nov. 2006. 
[23] D. Raca, P. Garcia, D. Reigosa, F. Briz, and R. Lorenz, "A comparative analysis of pulsating vs. rotating vector carrier signal injection-based sensorless control," in Applied Power Electronics Conference and Exposition (APEC), pp. 879 - 885, Feb. 2008.

[24] F. Gabriel, F. De Belie, P. Sergeant, and X. Neyt, "Modelling the impact of the stator currents on inductance-based sensorless control of brushless dc-machines," in Symposium on Sensorless Control for Electrical Drives (SLED), pp. 56 - 63, IEEE, Sept. 2011.

[25] S. Wu, D. Reigosa, Y. Shibukawa, M. Leetmaa, R. Lorenz, and Y. Li, "Interior permanent-magnet synchronous motor design for improving self-sensing performance at very low speed," IEEE Transactions on Industry Applications, vol. 45, pp. 1939 - 1946, Nov. 2009.

[26] E. Kayikci and R. Lorenz, "Self-sensing methods extended to four phase switched reluctance machines," in Power Electronics Conference (IPEC), pp. 2016 - 2023, June 2010.

[27] D. Reigosa, P. Garcia, F. Briz, D. Raca, and R. Lorenz, "Modeling and adaptive decoupling of high-frequency resistance and temperature effects in carrier-based sensorless control of pm synchronous machines," IEEE Transactions on Industry Applications, vol. 46, pp. 139 - 149, Jan. 2010

[28] F. De Belie, T. Vyncke, and J. Melkebeek, "Parameterless rotor position estimation in a direct-torque controlled salient-pole pmsm without using additional test signals," in International Conference on Electrical Machines (ICEM), pp. 1 - 6, Sept. 2010.

[29] F. De Belie, P. Sergeant, and J. Melkebeek, "A sensorless drive by applying test pulses without affecting the average-current samples," IEEE Transactions on Power Electronics, vol. 25, pp. 875 - 888, Apr 2010.

[30] P. Garcia, F. Briz, D. Reigosa, C. Blanco, and J. M. Guerrero, "On the use of high frequency inductance vs. high frequency resistance for sensorless control of ac machines," in Symposium on Sensorless Control for Electrical Drives (SLED), pp. 90 - 95, Sept. 2011.

[31] L. Gong and Z. Zhu, "A novel method for compensating inverter nonlinearity effects in carrier signal injection-based sensorless control from positive-sequence carrier current distortion," IEEE Transactions on Industry Applications, vol. 47, pp. 1283 - 1292, May 2011.

[32] N. Limsuwan, T. Kato, C.-Y. Yu, J. Tamura, D. Reigosa, K. Akatsu, and R. Lorenz, "Secondary resistive losses with high-frequency injectionbased self-sensing in ipm machines," in Energy Conversion Congress and Exposition (ECCE), pp. 622 - 629, Sept. 2011.

[33] N. Limsuwan, Y. Shibukawa, D. Reigosa, and R. Lorenz, "Novel design of flux-intensifying interior permanent magnet synchronous machine suitable for self-sensing control at very low speed and power conversion," IEEE Transactions on Industry Applications, vol. 47, pp. 2004 2012, Sept. 2011.

[34] S.-C. Yang and R. Lorenz, "Analysis of iron and magnet losses in surface permanent magnet machines resulting from injection-based self-sensing position estimation," in Energy Conversion Congress and Exposition (ECCE), pp. 630 - 637, Sept. 2011.

[35] S.-C. Yang and R. Lorenz, "Surface permanent magnet synchronous machine self-sensing position estimation at low speed using eddy current reflected asymmetric resistance," in Power Electronics and Applications (EPE), pp. 1 - 10, Sept. 2011.

[36] S.-C. Yang, T. Suzuki, R. Lorenz, and T. Jahns, "Surface-permanentmagnet synchronous machine design for saliency-tracking self-sensing position estimation at zero and low speeds," IEEE Transactions on Industry Applications, vol. 47, pp. 2103 - 2116, Sept. 2011.

[37] N. Bianchi, S. Bolognani, J.-H. Jang, and S.-K. Sul, "Comparison of pm motor structures and sensorless control techniques for zero-speed roto position detection," IEEE Transactions on Power Electronics, vol. 22 pp. $2466-2475$, Nov. 2007

[38] N. Bianchi and S. Bolognani, "Sensorless-oriented design of pm motors," IEEE Transactions on Industry Applications, vol. 45, pp. 1249 1257, July 2009.

[39] Z. Zhu and L. Gong, "Investigation of effectiveness of sensorless operation in carrier-signal-injection-based sensorless-control methods," IEEE Transactions on Industrial Electronics, vol. 58, pp. 3431 - 3439 Aug. 2011.

[40] I. Brown and R. Lorenz, "Induction machine design methodology for self-sensing: Balancing saliencies and power conversion properties," IEEE Transactions on Industry Applications, vol. 47, pp. 79 - 87, Jan. 2011.

[41] A. Faggion, N. Bianchi, and S. Bolognani, "Ringed-pole permanentmagnet synchronous motor for position sensorless drives," IEEE Transactions on Industry Applications, vol. 47, pp. 1759 - 1766, July 2011.

[42] M. Morandin, S. Bolognani, and A. Faggion, "Outer-rotor ringed-pole spm starter-alternator suited for sensorless drives," in Symposium on
Sensorless Control for Electrical Drives (SLED), pp. 96 - 101, Sept. 2011.

[43] H. Kim, M. Harke, and R. Lorenz, "Sensorless control of interior permanent-magnet machine drives with zero-phase lag position estimation," IEEE Transactions on Industry Applications, vol. 39, pp. 1726 1733, Nov. 2003.

[44] G. Wang, R. Yang, and D. Xu, "Dsp-based control of sensorless ipmsm drives for wide-speed-range operation," IEEE Transactions on Industrial Electronics, vol. 60, pp. 720 - 727, Feb. 2013.

[45] C. Silva, G. Asher, and M. Sumner, "Hybrid rotor position observer for wide speed-range sensorless pm motor drives including zero speed," IEEE Transactions on Industrial Electronics, vol. 53, pp. 373 - 378 , Apr. 2006.

[46] F. Demmelmayr, M. Susic, and M. Schroedl, "Sensorless control at high starting torque of a $4000 \mathrm{~nm}$ traction drive with permanent magnet synchronous machine," in Conference on Power Electronics and Applications (EPE), pp. 1 - 8, Sept. 2011.

[47] P. Landsmann, D. Paulus, and R. Kennel, "Online identification of load angle compensation for anisotropy based sensorless control," in Symposium on Sensorless Control for Electrical Drives (SLED), pp. 80 - 84, Sept. 2011.

[48] F. D. Belie, J. Melkebeek, K. Geldhof, L. Vandevelde, and R. Boel, "A general description of high-frequency position estimators for interior permanent-magnet synchronous motors," in International Conference on Electrical Machines (ICEM), Sept. 2004.

[49] P. Sergeant, F. De Belie, and J. Melkebeek, "Effect of rotor geometry and magnetic saturation in sensorless control of pm synchronous machines," IEEE Transactions on Magnetics, vol. 45, pp. 1756 - 1759, Mar. 2009.

[50] P. Sergeant, F. De Belie, and J. Melkebeek, "Rotor geometry design of an interior permanent-magnet synchronous machine for more accurate sensorless control," in International Conference on Electrical Machines (ICEM), pp. $1-6$, Sept. 2010.

[51] P. Landsmann, C. M. Hackl, and R. Kennel, "Eliminating all machine parameters in encoderless predictive torque control without signal injection," in International Electric Machines and Drives Conference (IEMDC), pp. 1259 - 1264, May 2011.

[52] R. Raute, C. Caruana, C. Staines, J. Cilia, N. Teske, M. Sumner, and G. Asher, "A review of sensorless control in induction machines using hf injection, test vectors and pwm harmonics," in Symposium on Sensorless Control for Electrical Drives (SLED), pp. 47 - 55, Sept. 2011.

[53] W. Jianmin and G. Jianwei, "Analysis of position estimation error resulted from filter in carrier signal injection based sensorless control of pmsm," in Conference on Electrical Machines and Systems (ICEMS), pp. $1-6$, Aug. 2011.

[54] P. Sergeant, F. De Belie, L. Dupre, and J. Melkebeek, "Losses in sensorless controlled permanent-magnet synchronous machines," IEEE Transactions on Magnetics, vol. 46, pp. 590 - 593, Feb. 2010.

[55] S.-C. Yang and R. Lorenz, "Surface permanent magnet synchronous machine position estimation at low speed using eddy-current-reflected asymmetric resistance," IEEE Transactions on Power Electronics, vol. 27 , pp. 2595 - 2604, May 2012.

[56] R. Leidhold and P. Mutschler, "Interaction between the current controller and the injection of alternating carriers in sensorless drives," in International Symposium on Power Electronics, Electrical Drives, Automation and Motion (SPEEDAM), pp. 262 - 267, June 2008.

[57] P. Vas, Electrical Machines and Drives: A Space-Vector Theory Approach. United States: Oxford University Press, 1993.

[58] L. Gong and Z. Zhu, "Saliency investigation of pm brushless ac motors for high-frequency carrier signal injection-based sensorless control," in International Conference on Automation and Computing (ICAC), pp. 86 - 91, Sept. 2011.

[59] A. V. Oppenheim and R. W. Schafer, Digital signal processing. PrenticeHall, 1975.

[60] H. Kim and R. Lorenz, "Carrier signal injection based sensorless control methods for ipm synchronous machine drives," in Industry Applications Conference (IAS), vol. 2, pp. 977 - 984, Oct. 2004.

[61] J. Hu, J. Liu, and L. Xu, "Eddy current effects on rotor position estimation and magnetic pole identification of pmsm at zero and low speeds," IEEE Transactions on Power Electronics, vol. 23, pp. 2565 -2575 , Sept. 2008

[62] T. J. S.-K. S. Yu-seok Jeong, R.D. Lorenz, "Initial rotor position estimation of an interior permanent-magnet synchronous machine using carrier-frequency injection methods," IEEE Transactions on Industry Applications, vol. 41, pp. 38 - 45, Jan. 2005.

[63] C.-Y. Yu, J. Tamura, D. Reigosa, and R. Lorenz, "Position self-sensing evaluation of a fi-ipmsm based on high frequency signal injection 
methods," in Energy Conversion Congress and Exposition (ECCE), pp. $3029-3036$, Sept. 2011.

[64] F. Gabriel, F. De Belie, P. Druyts, and X. Neyt, "Strategy to detect and prevent the current zero-crossing for inverter powered drives," in International Conference on Electrical Machines (ICEM), pp. 1 - 6, IEEE, Sept. 2010.

[65] H. Kim, K.-K. Huh, R. Lorenz, and T. Jahns, "A novel method for initial rotor position estimation for ipm synchronous machine drives," IEEE Transactions on Industry Applications, vol. 40, pp. 1369 - 1378, Sept. 2004.

[66] H. Mai, F. Dubas, D. Chamagne, and C. Espanet, "Optimal design of a surface mounted permanent magnet in-wheel motor for an urban hybrid vehicle," in Vehicle Power and Propulsion Conference (VPPC), pp. 481 - 485, Sept. 2009.

[67] F. Gabriel, F. De Belie, and X. Neyt, "Inductance-based position selfsensing of a brushless dc-machine using high-frequency signal injection," in Conference of the IEEE Industrial Electronics Society, IEEE, octobre 2012.

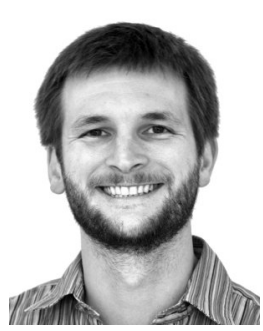

Fabien Gabriel received the master degree in Electromechanical Engineering from the Université Libre de Bruxelles (ULB), Belgium, in 2004. Since 2007, he has been working as research engineer for the Royal Military Academy, Belgium, in the Dept. of Communication, Information, Systems and Sensors (CISS). His research interests include electric machine drives and control techniques without position/motion sensor. He is currently working toward the Ph.D. degree.

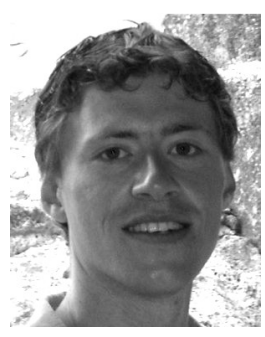

Frederik De Belie was born in Belgium in 1979. He received the Master Degree in Electromechanical Engineering from Ghent University, Ghent, Belgium, in 2002. Since then, he has been with the Electrical Energy Laboratorium (EELAB), UGent. In March 2010 he received the Ph.D. degree from Ghent University and in December of the same year he was awarded the Biennial Iwan Akerman Award from Atlas Copco nv in corporation with the FWO and FNRS for his work on sensorless control. At the moment, he's an assistant professor at EELAB, UGent. His present research interests include dynamic-modelling theory and control-system theory applied to electrical drives and, in particular, sensorless control of synchronous machines. He has been involved in several projects concerning electric drives in renewable energy sources. He is co-inventor in a patent application on sensorless control of salient-pole machines.

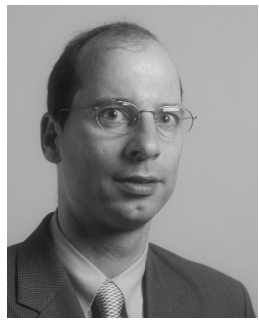

Xavier Neyt received the M.S. degree (summa cum laude) in engineering from the Université Libre de Bruxelles (ULB), Brussels, Belgium in 1994, the M.S. degree (summa cum laude) in signal processing from the Université de Liège (ULg), Liège, Belgium, in 2004, and the Ph.D. degree in applied sciences from the Royal Military Academy (RMA), Brussels, and the ULg in 2008. He was a Visiting Scientist with the French Aerospace Research Center (ONERA) in 1996-1997 and with the German Aeropspace Center (DLR) in 1999. He was responsible for the design of the image compression module of the European Meteosat Second Generation satellite in 1997-1999 and responsible for the redesign of the ground processing of the scatterometer of the European Remote Sensing satellite following its gyroscope anomaly in 2000-2007. Since 2008, he has been a Research Engineer with the RMA, where he has been leading the Scatterometer Engineering Support Laboratory for the European Space Agency and is currently an Associate Professor with the Department of Communication, Information, Systems and Sensors. His research interests are radar remote sensing, array processing, and bistatic radars. Prof. Neyt was a recipient of the Frerichs Award from the ULB and the special IBM grant from the Belgian National Fund for Scientific Research (NFWO) in 1995. He also serve on the Radar Systems Panel of the IEEE Antenna and Electronic Systems Society.

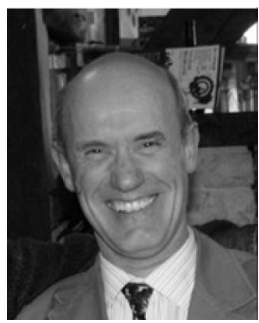

Philippe Lataire received a degree in electromechanical engineering in 1975 and a degree in doctor in applied sciences in 1982 from the Vrije Universiteit Brussel (VUB, Brussels, Belgium). He is presently full professor at the VUB in the field of power electronics, automatic control and electric drives. The prime factors of his research interest are in the field of electric drives, power electronics and control. The Department FirW - ETEC, headed by Prof. Philippe Lataire, developed research activities in the fields of sustainable mobility, computational electrochemistry, lighting, electric machines and power electronics applications. 